\title{
An Improved Colony Illuminator
}

\author{
By W. T. MOORE AND C. B. TAYLOR \\ Imperial Chemical Industries Ltd., Butterwick Research Laboratories, \\ The Frythe, Welvoyn, Hertfordshire
}

SUMMARY: A colony illuminator is described which incorporates side illumination by means of a small ring fluorescent tube. Inspection of the Petri dish is facilitated by the use of a detachable 5 in. diameter plastic industrial inspection lens.

For some years the need has been felt for a good colony illuminator, for colony counts or morphological studies. Recent developments in the manufacture of fluorescent tubes and of plastic inspection lenses have allowed us to design an illuminator which not only provides good lighting but relative freedom from eye strain when the instrument is used for long periods. In the past, most

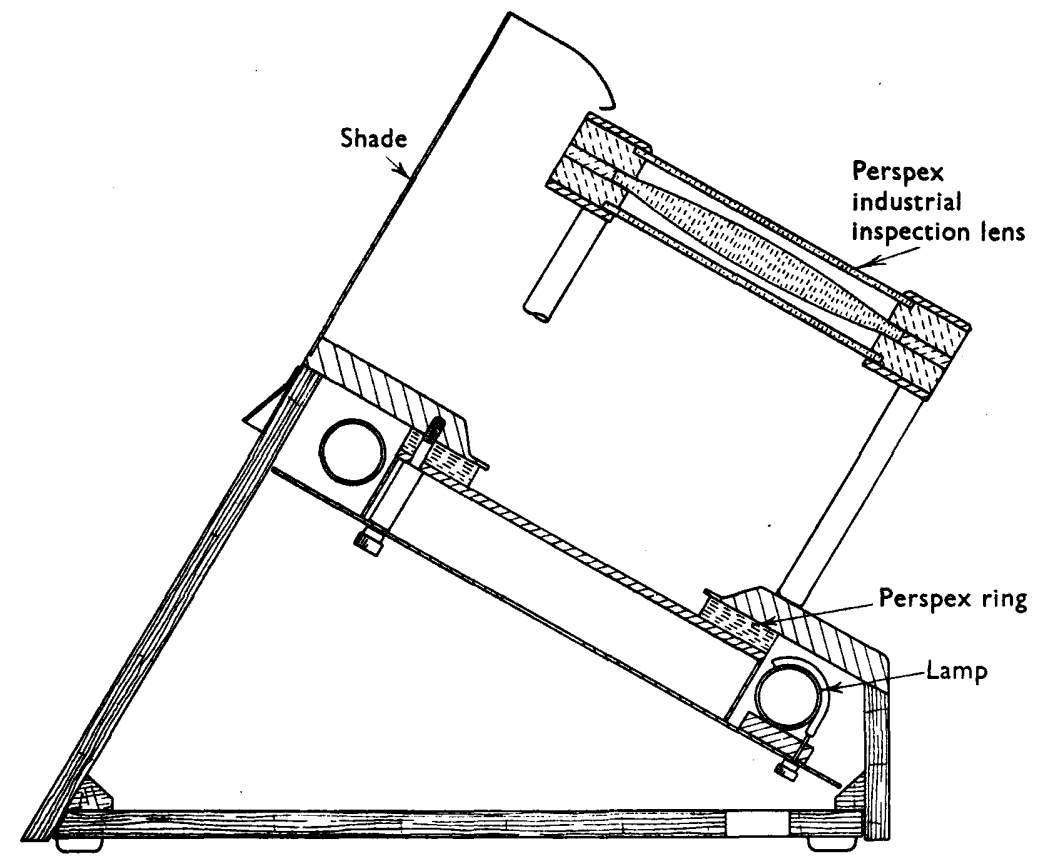

Fig. 1. Diagrammatic arrangement of colony illuminator $\left(\times \frac{1}{2}\right)$.

counting chambers have employed diffused lighting through the base of the Petri dish, but Crisp (1940) described a chamber in which side lighting was used; a beam of light passed through a rectangular slot at the side of the Petri dish, and the colonies appeared in relief (by the shadows).

Our illuminator (Fig. 1 and Pl. 1) consists of a sloping box on which the Petri dish rests. A ring fluorescent lamp 8 in. diameter (Longlamps Ltd., Marshalsea 
Journal of General Microbiology, Vol. 4, No. 3

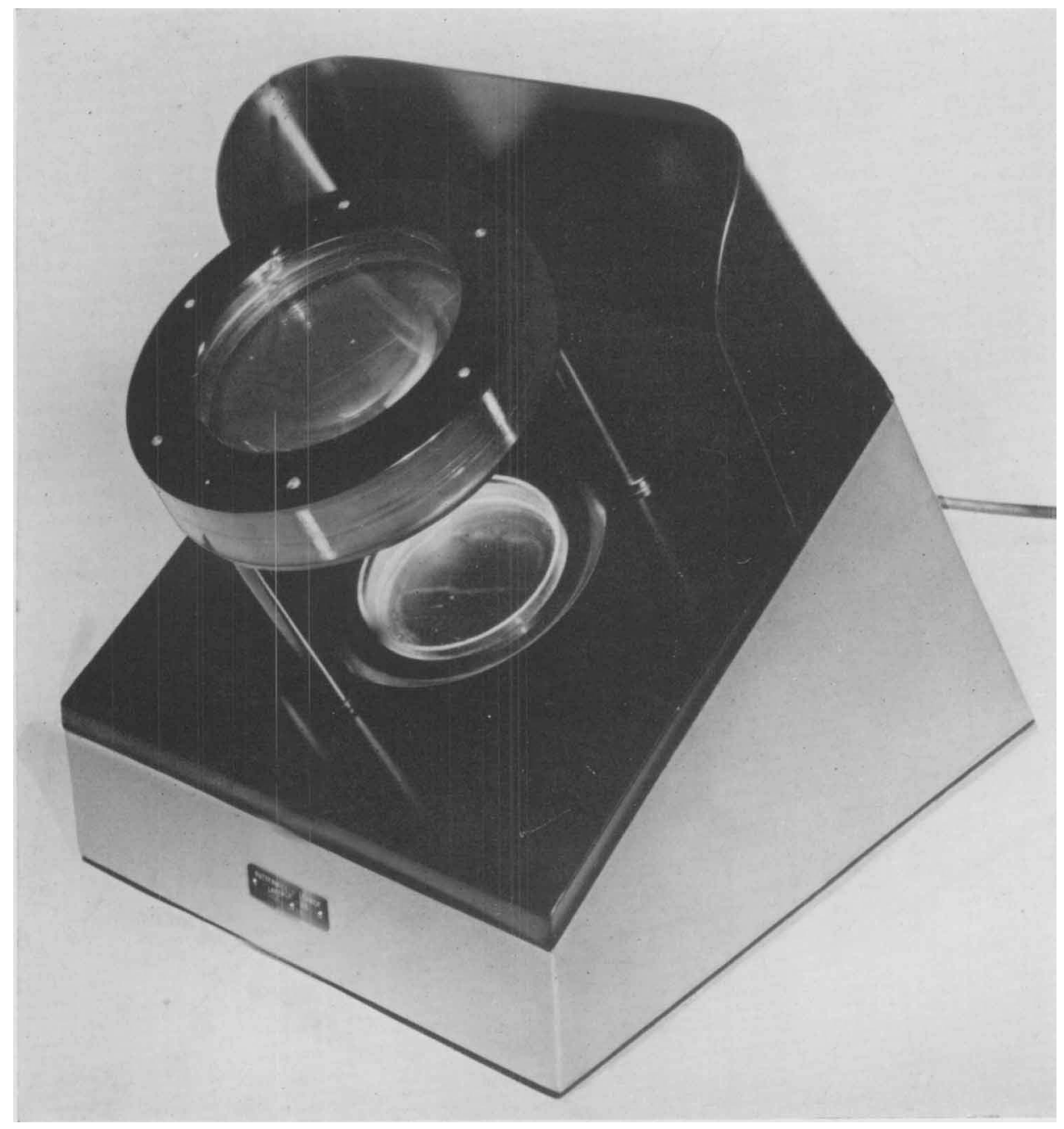

The improved colony illuminator

W. T. Moore \& C. B. Taylor-An improved colony illuminator. Plate 1 
Road, London, S.E. 1), surrounds the dish and provides the illumination; a ring of Perspex placed between lamp and dish carries the light to the edge of the dish. The low temperature of the fluorescent lamp ensures that the chamber is not overheated. Further to this end the choke, which becomes warm after use, is housed in the three-pin plug.

$A 5$ in. diameter $\times \mathbf{2}$ plastic industrial inspection lens (Imperial Chemical Industries Ltd., Plastics Division) is supported over the dish on three legs. Two of the legs slide into sockets thus ensuring that the lens is rigidly held but easily removed. The lens is designed for use at a distance of 6 in. from the eyes and provides a substantially distortion-free image which can be observed with both eyes simultaneously. Ruled paper counting disks may be inserted under the dish if required.

\section{REFERENCE}

Crisp, A. E. (1940). A counting lamp for colonies of bacteria. J. sci. Instrum. 17, 70. 